\title{
12 The development of the Chinese animation industry in 2017
}

\author{
Hong Lu
}

\section{Overview of the Chinese animation film market in 2017}

In 2017, the total revenue from the box office of Chinese films totaled 52.6 billion yuan (excluding online ticketing fees), a year-on-year increase of 15.1 percent. The Chinese film box office totaled 28.3 billion yuan, accounting for 53.8 percent of the total box office. Some 92 films created a box office revenue of over 100 million yuan each, including 51 Chinese films, and 15 films generated box office revenue of more than 1 billion yuan, an increase of nearly 70 percent compared with 2016. A total of 1.62 billion movie tickets were sold in urban cinemas with a growth of 18.08 percent since 2016 . The total number of cinema screens in China reached 50,776, surpassing that of America, making China rank first in the world. According to Figure 12.1, Chinese films' box office in 2015-2017 remained within a relatively stable range. Figure 12.2 shows that the growth rate of the Chinese box office dropped significantly in 2016 compared with that of 2015. However, in 2017, it rose successfully. Phenomenal films such as Wolf Warrior 2 and Never Say Die have helped the box office to rise again, maintaining a steady upward trend from 2015 to 2017. Many insiders believe that Chinese film market is gradually returning to profitability.

In contrast to the considerable success of China's animation film market in 2016, the performance in 2017 was poor with 10 million animation film screenings and 140 million tickets sold. In 2016, there were 12 million screenings and 220 million tickets sold, showing a decrease of 19 percent and 36 percent respectively. In 2017, the total box office was 4.7 billion yuan, a 41 percent year-on-year decrease, the first decline in the past five years (Figure 12.3).

A total of 52 animation films were released in 2017, which is 13 less than in 2016. The total in 2017 includes 29 domestic animation films, which was 8 less than in 2016, and 21 imported animation films and 2 domestic coproductions, which decreased by 2 and 3 from 2016 respectively (Figure 12.4).

The number of Chinese animation films in 2017 was 8 less than in 2016, but the total box office was 1.296 billion yuan which is 3 million yuan higher than in 2016 (Figure 12.5). This shows that the decline in the total box office 


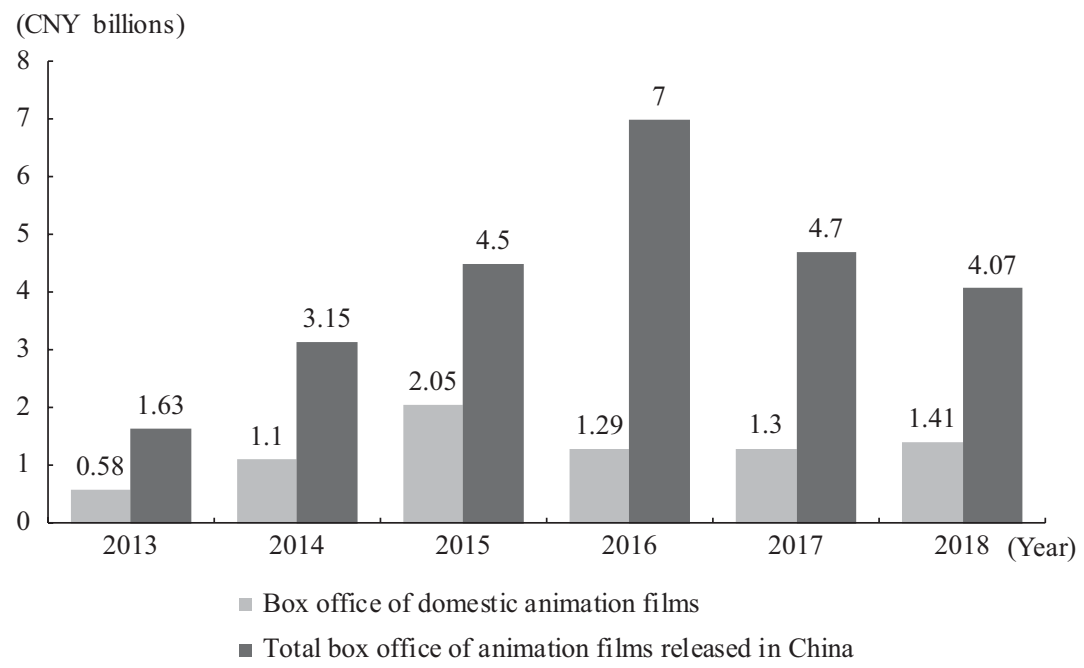

Figure 12.1 China's film market box office, 2013-2018.

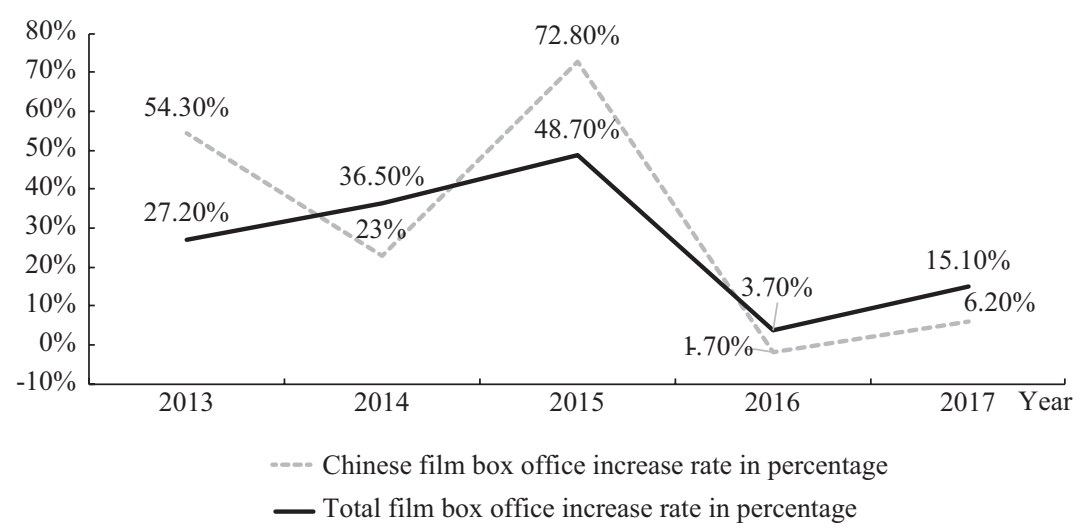

Figure 12.2 A comparison of the Chinese film market's increase rate, 2013-2017.

of animation films is reflected in imported film and co-productions, of which the box office totaled 3.365 billion yuan, a 2.425 billion yuan decrease from that of 5.80 billion yuan in 2016 .

In 2017, the average box office of domestic animation films was 44.69 million yuan with 31 percent of the average of imported and co-produced animations (146 million yuan), which was almost the same as 32 percent in 2014. Although the figures were much lower than 45 percent in 2015, they were much higher 


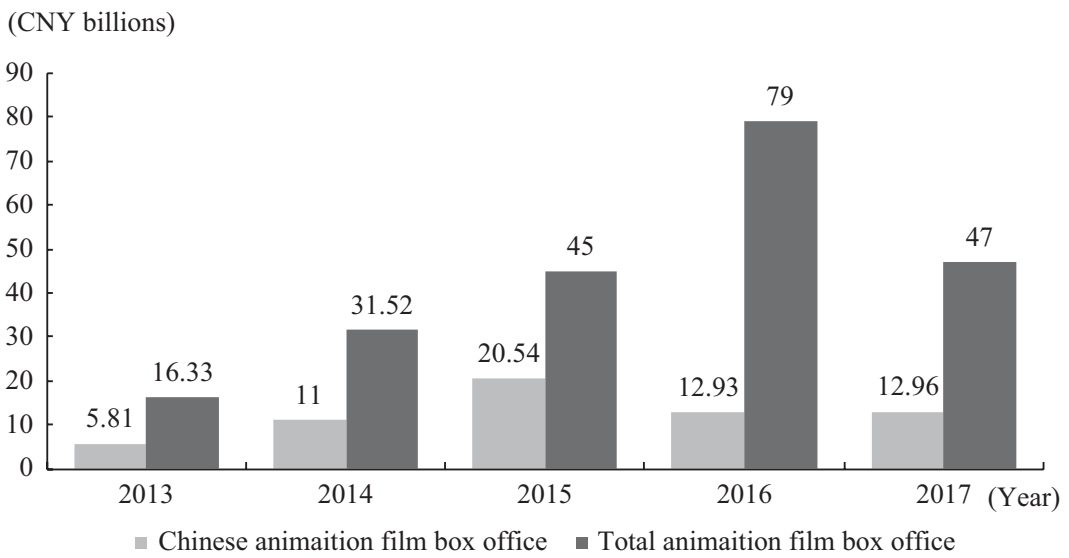

Figure 12.3 Chinese animation film box office, 2013-2017.

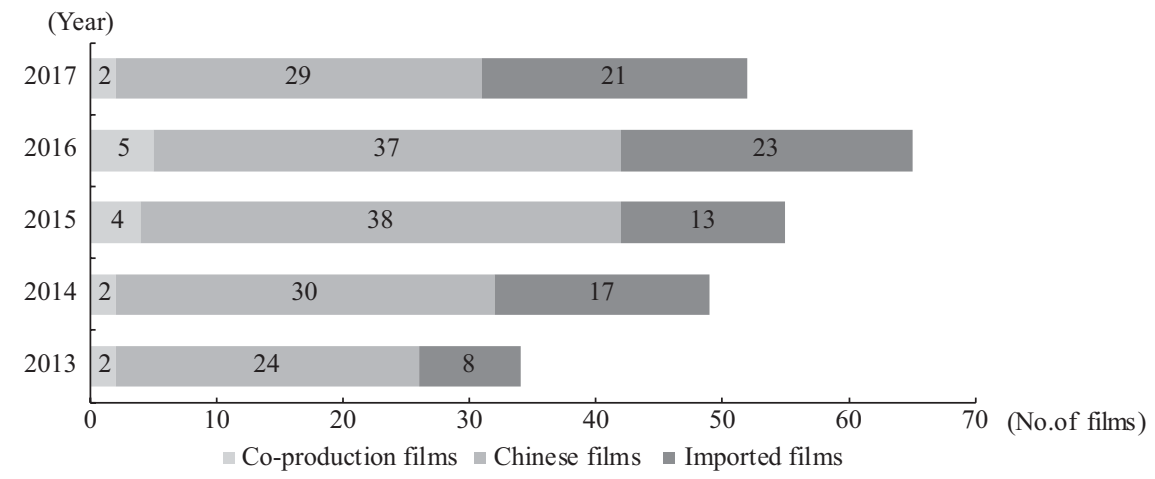

Figure 12.4 Types of animation films of China, 2013-2017.

than in 2016 which was only 17 percent. Three major reasons account for the box office performance of animation films in 2017 as detailed below.

One reason is that blockbusters, such as Monkey King: Hero Is Back (2015), that can create a cultural trend with social topics, were missing in 2017. Although "Three Giants": Dahufa, Bigfish Begonia, and Monkey King by Enlight Media did appear, the target audiences are mostly adults due to the "special" themes of the films. As a result, the audience pool will be relatively small, hence, it cannot form a nationwide viewing passion for films such as Monkey King: Hero Is Back.

The second reason is that Chinese animation films are facing strong competitors - a large number of imported films. Although the box office of 


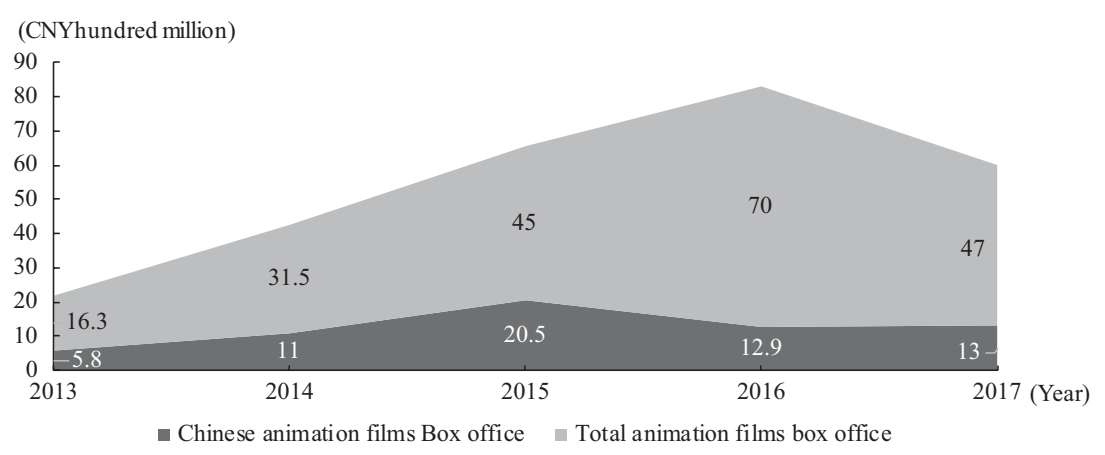

Figure 12.5 Trend of China's animation film box office, 2013-2017.

imported and co-produced animation films in 2017 has declined, the release date of Coco, the box office champion of animation films in 2017, was in late November 2017. In this chapter, the box office statistics cycle is based on the calendar year. Coco ranked top of the box office of animation films in 2017, reaching 1.1 billion yuan within a month. If Coco had been released in the first half of 2017, the figures would be similar to that of Zootopia which was released in March 2016. Coco's box office could be higher than the box office of Zootopia which is 1.5 billion yuan. Chinese animation films do not compare well to Hollywood productions in terms of production quality and successful animation Internet Protocol (IP) projects.

The third reason is that the number of Chinese animation films has decreased without affecting its box office, which shows that, with policy support and industrial efforts, Chinese animation films have gradually gained an important position among Chinese audiences. A growing number of Chinese audiences now enjoy watching Chinese animation films in cinemas. Viewing habits have been changed by the tireless efforts of Chinese animators and investment companies over the years. Recognizing the audiences, in order to meet the growing demand of the public, Chinese animation filmmakers should continue to produce different types of excellent animation films for the different target audiences.

In 2017, the number of Chinese animation films recorded by the National Radio and Television Administration of China was 156, 26 fewer than in 2016, which was 182, but still higher than in 2015 (Figure 12.6).

According to the 2017 box office ranking for Chinese animation films, if a threshold of 100 million yuan in box office is set, ten films meet this record. The US and Japan are China's main competitors at the animation film box office. Of the top ten, the US accounts for five films, Japan accounts for one, and China, four (Table 12.1). In 2016, only two Chinese films were in the top ten for global animation films, while in 2015, there were three, and in 2014, there were four. Animation films are facing more and more pressure 


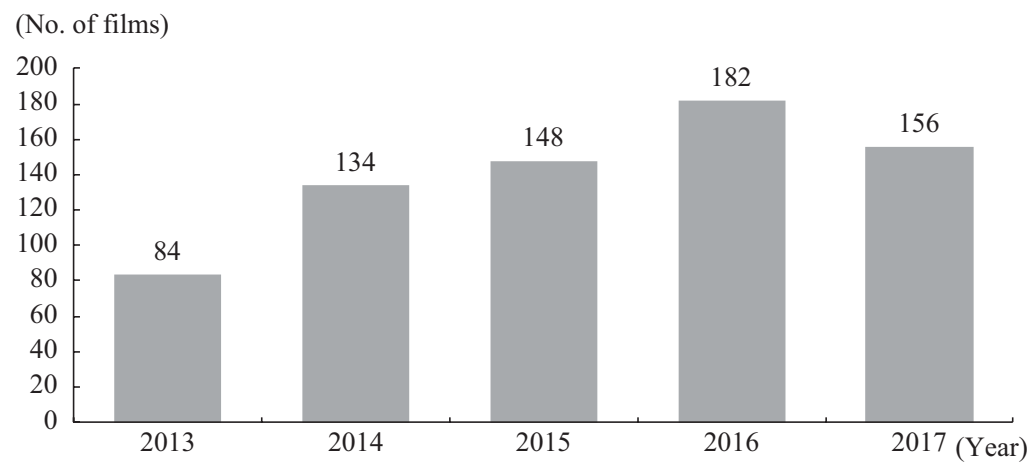

Figure 12.6 Chinese animation film record, 2013-2017.

Table 12.1 Animation films in China with box office over 100 million yuan

\begin{tabular}{lllll}
\hline $\begin{array}{l}\text { Ranking in } \\
\text { animated } \\
\text { film }\end{array}$ & $\begin{array}{l}\text { Ranking } \\
\text { in all } \\
\text { films }\end{array}$ & Title & $\begin{array}{l}\text { Box office } \\
\text { (¥ 100 } \\
\text { million) }\end{array}$ & $\begin{array}{l}\text { Country } \\
\text { of origin }\end{array}$ \\
\hline 1 & 11 & Coco & 11.53 & USA \\
2 & 15 & Despicable Me 3 & 10.38 & USA \\
3 & 32 & Boonie Bears: Entangled Worlds & 5.22 & China \\
4 & 60 & Sing & 2.16 & USA \\
5 & 69 & Smurfs: The Lost Village & 1.74 & USA \\
6 & 76 & Doraemon Nobitas Great Adventure & 1.49 & Japan \\
7 & 78 & in the Antarctic Kachi Kochi & & Cars 3 \\
8 & 80 & One Hundred Thousand Bad Jokes II & 1.37 & China \\
9 & 81 & Backkom Bear: Agent O08 & 1.26 & China \\
10 & 92 & Seer Movie 6: Invincible Puni & 1.03 & China \\
\hline \multicolumn{5}{c}{}
\end{tabular}

from the trend of diversification in other countries, and the types of imported films. With the acceptance of other imported films in addition to the US and Japan, the Chinese animation film market is likely to be further occupied by imported animation films. Although this has not yet happened, Chinese filmmakers must make long-term efforts to understand the need of audiences and produce animation films with new themes, in different genres and with high production quality.

While in 2016 there were two animation films in China's top ten box office, in 2017, no Chinese animation films ranked in the top ten. The animation box office champion Coco ranked 11th, and Despicable Me 3, which was hugely popular, ranked 15 th. The author believes that such popularity was related to the phenomenal film Wolf Warrior 2 in 2017. After Wolf Warrior 2 was 
released in late July, it created a strong competition in the market where animation films achieved great performance at the box office in summer 2017.

According to Entdata, 82 films were released during the traditional summer vacation from July 1 to August 31, 2017, with a total of 16.43 million screenings. Wolf Warrior 2 ranked first at the box office (5.679 billion yuan) and in screenings (4.16 million times). For the number of screenings, Wolf Warrior 2 accounted for one quarter of all 82 films. A total of 12 animation films were released, with a total of 3.14 million screenings, while Wolf Warrior 2 had one million more screenings than all animation films in total. In 2016, 91 films were released in the summer, with 13.65 million screenings. Time Raiders ranked first at the box office (1.004 billion yuan) with the most screenings (1.03 million times) too. A total of 16 animation films were released with 3.23 million screenings. In 2016, the total box office champion, Mermaid by Stephen Chow, had 2.11 million screenings.

By comparing the figures, we can see that the scheduling and number of screenings have a great impact on a film's box office success. In 2015, the movie Monkey King: Hero Is Back was not circulated much on its opening. Due to outstanding word of mouth and market response, more screenings were arranged, and the release period was extended. Finally, the film generated over 900 million yuan box office revenue, which was a huge success. Of course, scheduling is only one of the factors impacting the box office sales. With its good reputation and consistent high quality, Despicable Me 3, which was scheduled during the same time as Wolf Warrior 2, received the second highest box office revenue among 82 films in the summer, which follows closely behind Wolf Warrior 2. From Monkey King: Hero Is Back to Despicable Me 3, the high quality of films is always the key factor to seize the market and increase their popularity with audiences.

At the beginning of 2017, the New Year movie Bonnie Bears: Entangled Worlds again broke the record with a box office of 522 million yuan, which showed that the series continued to be popular and it nearly doubled the box office of 288 million yuan compared to Bonnie Bears: The Big Top Secret in 2016. It moved in rank up from the 8th to the 3rd in the animation films' box office from 2016 to 2017 and replaced Pleasant Goat and Big Big Wolf as the new leader of the Chinese animation series. The latter has not released any new series for two consecutive years. Dahufa, one of the "Three Giants" (Dahufa, Bigfish Begonia, Monkey King) from Enlight Media, was released at the same time (in the summer of 2016) as Bigfish Begonia. However, because Dahufa's adult theme is different from Bigfish Begonia and Monkey King, its less popular unique world-view and the degree of violence made it only suitable for a small public, and its final box office revenue was just 87.6 million yuan.

In 2017, there were 32 animation films with over 10 million yuan at the box office, including 14 Chinese animation films (Table 12.2), which is an increase of 6 from 2016. The box office is as follows: 1 animation film exceeding 500 million yuan (same as 2016); and 3 animation films exceeding 100 million 
Table 12.2 Chinese animation films with over 10 million box office in 2017

\begin{tabular}{rll}
\hline No. & Title & Box office (¥ 10,000) \\
\hline 1 & Bonnie Bears: Entangled Worlds & 52248 \\
2 & One Hundred Thousand Bad Jokes II & 13364 \\
3 & Backkom Bear: Agent 008 & 12636 \\
4 & Seer Movie 6: Invincible Puni & 10329 \\
5 & Dahufa & 8760 \\
6 & Axel: Adventures of the Spacekids & 5041 \\
7 & Dear Tutu: Food Rhapsody & 4298 \\
8 & GG Bond series: Guarding & 4247 \\
9 & T-Guardians & 4071 \\
10 & Dragon Force Movie & 3169 \\
11 & Tea Pets & 3040 \\
12 & The Three Little Pigs 2 & 2461 \\
13 & Tofu & 1591 \\
14 & My King My Father & 1570 \\
\hline
\end{tabular}

yuan (an increase of 1 from 2016). Overall, Chinese animation films still achieved good results. Some 18 of 23 imported, and co-produced animation films exceeded 10 million yuan in box office, of which Coco and Despicable Me 3 reached 1 billion yuan. It shows that the overall quality of Chinese animation films has improved, gaining an increase of the overall market box office and word of mouth popularity. However, the Chinese animation film industry does not have influential blockbusters. So far, Monkey King: Hero Is Back is the film with the highest box office revenue of 956 million yuan, which is still less than 1 billion yuan.

Compared with imported films, Chinese animation films are often released during the Spring Festival holiday season, Children's Day, summer vacation, and Chinese National Day Golden Week (Figure 12.7). However, the number of screenings, movie tickets sold, and box office revenue during these periods were not at the peak. On the contrary, sometimes these figures were low, which to some extent shows that the collective release of Chinese animation films will not be a key force leading the box office trend. What really made the monthly box office climb to the summit was the time when Hollywood's animation blockbusters were released, such as the July release of Despicable Me 3 and the November release of Coco (Figure 12.8). In January, 8 Chinese animation films were released, as well as 1 imported film from the US, Kubo and the Two Strings ranking the first place in the annual screenings with a monthly box office of nearly 700 million yuan and ranking 3rd in the whole year box office. Although there were no animation films released in June 2017, in order to warm up the film market for the Children's Day, four Chinese and two imported animation films were already released on May 27th, 28th and 30th, which was close to June. However, this strategy did not have much 


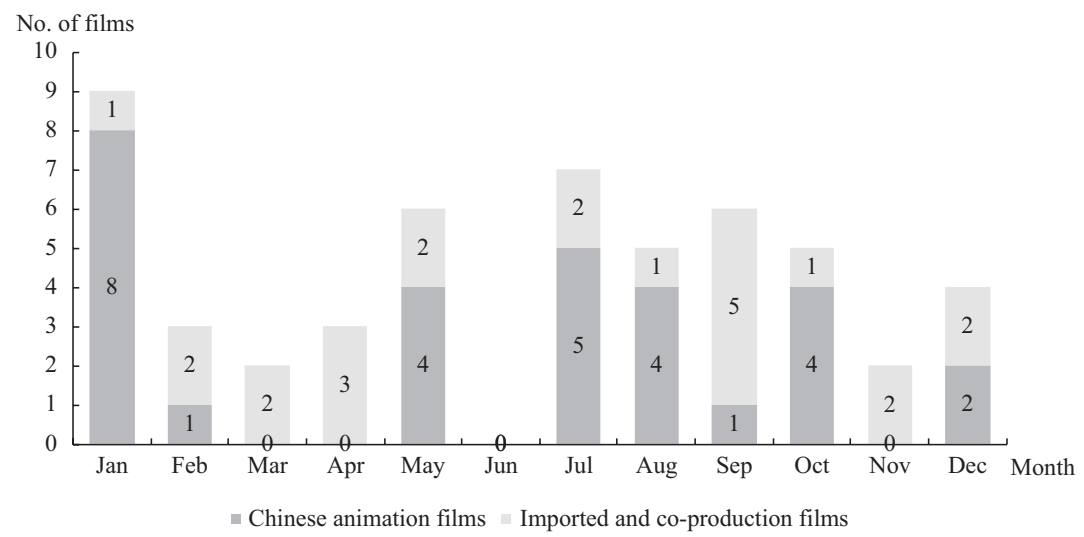

Figure 12.7 Number of animation films releases of 2017, by month.

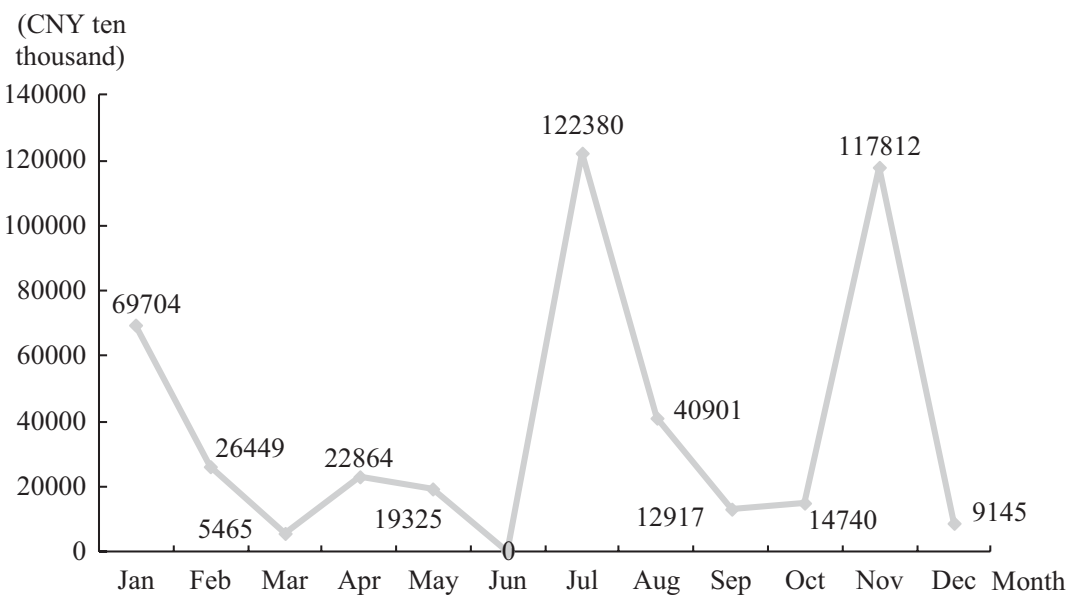

Figure 12.8 The trend of animation films' monthly box office of 2017.

influence on the box office. In the month of October, when Chinese National Day Golden Week starts, four domestic and one imported animation films were released. With four Chinese animation films released on October 1, the box office was still not satisfying. Therefore, better scheduling of screening in the holiday season for Chinese films cannot guarantee cinema admissions and box office. Even when the scheduling of the screening is favorable to Chinese animation films, they still face competition from live-action movies and the situation is not optimistic. 


\section{The industry characteristics of Chinese animation films in 2017}

According to the data from 2013 to 2017, the trend of Chinese animation films is relatively stable and its box office is growing slightly, which is the promising result of the focus on quantity and quality by Chinese animation filmmakers.

\section{The box office: steady increase and balanced development}

Unlike the Chinese animation film structure in 2016, which was not a stable pyramid shape, the performance of Chinese animation films' box office in 2017 is more stable. First, the number of films with a box office of more than 100 million yuan and more than 10 million yuan are, respectively, two and six more than those in 2016, with the premise that the number of films shown in cinemas in 2017 was eight fewer than in 2016. In 2017, the box office rose from 10 million yuan to 500 million yuan with Chinese animation films distributing at almost every interval, but only a few Chinese animation films had a box office of more than 10 million yuan in 2016. Second, all four films with a box office of more than 100 million yuan are sequels, namely, Bonnie Bears: Entangled Worlds, One Hundred Thousand Bad Jokes II, Backkom Bear: Agent 008 and Seer Movie 6: Invincible Puni, while in 2016, there was only one: Bonnie Bears: The Big Top Secret. It is an achievement that series films have been constantly improving for a long time. In addition to these 4 named 100 million yuan box office films, 10 of the other 25 Chinese animation films were also sequels. There are many popular intellectual property (IP) films occupying a certain market share, such as the Dear Tutu series Food Rhapsody, the GG Bond series Guarding, and the Dragon Force series Dragon Force Movie, etc.

Bonnie Bears: Entangled Worlds inherited the attractions from the Bonnie Bears series and became the year's highest-grossing Chinese animation film, which made 522 million yuan at the box office. As a 500 million yuan box office film, Bonnie Bears: Entangled Worlds is still not a blockbuster compared to Big Fish Begonia which made 560 million yuan and became the top Chinese animation film in 2016. The author believes that an animation film blockbuster should have the following characteristics: (1) the film suits audiences of all ages; (2) its theme is relevant to social topics of the year; (3) it has originality and uniqueness; and (4) it shares a common value with most people. Obviously, Bonnie Bears: Entangled Worlds does not have the necessary characteristics of a blockbuster. However, Coco, released in November 2017, was a true blockbuster in this sense, because of its unique and splendid representation of the world, an emotional story, its suitability to audience of all ages and universally accepted values. Similar to Zootopia and Monkey King: Hero Is Back, the film Big Fish Begonia attracted great interest from investors and audiences by a short Flash video published eight years ago, and after several years' long wait. Based on the solid reputation of Monkey 
King: Hero Is Back, when Big Fish Begonia finally released in 2016, its exquisite and delicate images as well as the familiar but unique representation of the world made it a blockbuster. But there are some deficiencies in its values, which led to the lack of emotionality in the characters, the unrealistic plot, and the lack of dramatic tension. These shortcomings made it second to Monkey King: Hero Is Back at the box office. In 2017, Dahufa possesses the last three characteristics: uniqueness and innovativeness, a world-view similar to that of audiences, and relevance to social topics of the year. Unfortunately, it expressed a realistic theme with exaggerated animation techniques and a rather violent and dark plot that went beyond most Chinese people's appreciation of animation films. Audiences who went to the cinemas seeking entertainment were disappointed or confused. Many audiences, especially many families with children, left the cinema in the middle of the screening. Animation films with this type of theme can only attract limited audiences. However, it does not mean that films of minority interest are not good. Some filmmakers want to produce their own products, rather than a product that most people are willing to watch. The Chinese animation film market still lacks films with adult themes. The author thinks that the audience's aesthetic habits are slowly developing. As animation filmmakers, despite the desire for self-expression or to guide audiences to develop an aesthetic habit, they should make more animation films for adults in order to gain the market. Animation films are not only for children, but also for adults. In this way, the Chinese animation film market would eventually progress.

\section{The animation industry: a hotspot subdivision field of investment and financing}

According to incomplete statistics from yulezibenlun (WeChat: yulezibenlun), in 2017, there were 110 financing events for animation projects, with a total amount of 4.053 billion yuan (excluding 12 non-disclosure amounts). Compared to the 128 events and the amount of 2.886 billion yuan in 2016, though the number of events decreased in 2017, the amount of financing increased by 40.44 percent. In addition, a single financing amount in 2017 was 41.36 million yuan, which was much higher than in 2016 (26 million yuan). The capital invested by Tencent, Alibaba Group, and Bilibili almost equals that of venture capital firms by percentage.

When the number of core ACGN (Animation/Comic/Game/Novel) users in China reached 82 million and the number of pan-ACGN users surpassed 250 million, the huge demand of the market and the lack of industrial supply made Internet giants and venture capital firms continue to invest in the animation industry in the future.

According to the data on the top 50 animation financing events of 2017, they have the following characteristics. First, as the two most favored segments of the animation industry, platform financed events accounted for 66.26 percent and content provider (CP) financed events accounted for 46 percent. The 
financing stage of platform companies is mainly in series $\mathrm{C}$ and series $\mathrm{D}$, while the financing stage of $\mathrm{CP}$ production companies is focused on early start-up funds, Angels Invest, and series A.

Second, the range distribution of financing of 1 million yuan levels and 10 million yuan levels accounted for 89.8 percent in total, while those of 100 million yuan and above accounted for 8.16 percent. Although this was a slight increase compared with 5.48 percent in 2016, the single financing amount is still less than that of heavily invested sectors, such as the video sector.

Third, from the perspective of rounds, angel investment (Angels Invest) accounted for 25.45 percent in 2017 which is lower compared to the 43.75 percent invested in 2016. At the same time, nearly half of financing events (48.18 percent) were centered in pre-A/A/A + rounds, higher than 36.72 percent in 2016. This shows that the financing rounds of animation industry have a significant backward trend. It means that some animation enterprises have been firmly established and even become the leading enterprises in the industry.

Fourth, Tencent, Alibaba and Bilibili are more like venture capitalists than traditional venture capitalists. They are keen on investing in the animation sector and form an industrial closed loop: Tencent directly participated in 11 financing activities for 10 companies in 2017, which is higher than in 2016. Tencent's overall arrangement in the animation field has exceeded most of the Chinese domestic companies for a few years, and few companies can compete with it. In the past two years, Tencent's investment in the animation field suddenly accelerated, widening the gap with the rest of its industrial competitors. The overall layout of the pan-entertainment field has taken shape. Alibaba entertainment has been able to compete with Tencent. Youku Tudou Inc. has increased its investment in the animation field in the past two years and has participated in the production of many animation films, such as The Young Imperial Guard and Tea Pets, and has continuously moved resources to content creation. In 2017, Bilibili invested in five animation companies, becoming a force not to be ignored in the primary market of the animation industry. From virtual idol to the ACGN community, from games to animation derivatives, the investment projects of Bilibili appear to be diversified and unconventional.

The animation sector continues to be the segment with the highest investment and financing frequency in the recreation primary market. Capital investment is still continuously entering the animation market and such strong financial support proves the sustainable development of the animation industry. On the one hand, it is a signal that the Chinese animation industry has the scale and potential for sustainable development in the next few years. On the other hand, people should not expect to solve all the problems by relying on the capital investment of the past two years. Whether it is to get government support or capital investment, the products still need to be tested in the market. From getting investment to releasing the final product (films, 
television works or derivatives), the links, processes, departments and people involved need to be coordinated and managed scientifically. Without scientific management, even huge capital investment cannot produce positive final result.

The existing problems in the development of the Chinese animation industry are not new. Many experts have repeatedly mentioned them in their speeches, works and articles published in the past decade, such as inappropriate themes, lack of system rating, copyright infringement, too many sequels and lack of originality, unprofessional storytelling skills, and insufficient cinema scheduling, etc. It is not necessary to repeat the above problems and two new thoughts on these issues are shared as below.

First, the author believes that the reason for the unprofessional narrative structure is not about storytelling itself, nor plot setting, characters and their relationships, or cinematic pace control, but whether filmmakers clearly know what they want to express and what the core message of values a film tries to deliver. If they do not know, even for a film with a good theme, the story will not be able to achieve the expected impact among its audiences. The value of a film is like the foundation of a building: the whole building will crumble if its foundation is unstable. As mentioned above, the problem with the film Big Fish Begonia is that the views of the values of the characters conflict with the views of values of the audiences. The audiences do not self-identify with the characters. The demands, goals and ideals of the characters cannot be understood by the audience, hence there is no emotional resonance among the audiences. For example, recent popular American animation films such as Zootopia, the Kung Fu Panda series, Moana, the Finding Nemo series, Sing, Coco, and the Despicable Me series, all have very clear core values in their stories. They present values through the experiences and achievements of each character. These films are about how the characters realize their values through a series of events, and their relationship with other characters. Compared to live action films, the values of animation films are likely to be the same. However, they are often more positive, such as justice will prevail over evil, success belongs to those who persevere, being true to oneself, being courageous, having self-confidence and self-reliance, and willingness to help others, etc. If a filmmaker wants to be different, he/she needs to work hard and render the real world in an abstract animation format, for example, the role of the animal world in Zootopia, and the world of death in Coco. The values of a film are the soul of a work and the key to stimulate the audiences' emotional response.

Second, as mentioned above, it is a long and arduous journey to go from securing capital investment to the actual implementation of the project, and the final product release in the market. In this process, it is the production management team that leads the creative team to complete the project step by step with confidence, goals and plans. A good production management team can make a low-cost film a success, while a poor production management team can make a very expensive film a failure. An excellent 
production management team must have the following qualities: (1) they can understand the process and rules of animation production; (2) a team has specialists to formulate technical solutions and provide corresponding cost budgets for the creative team and its investors; and (3) the team should have rich experience in financial management, legal management, and production management, and be able to review the situation, and coordinate between the creative team and its investors. If the Chinese animation film industry wants to make continuous and rapid development, it is equally urgent and crucial to educate animation production management talents as well as creative animation talents. 